Jadwiga Szymańska-Pętala

KULTURA PIŚMIENICZA KSIAG PARAFIALNYCH W WARSZAWIE

W PIERTSZM OKRESIE STOEzCZNOŚSCI MIASTA, DO $1655 \mathrm{ROKU}^{1}$

Powszechnio wladomo, ze kultura jest ndobrem zbiorowym 1 zbiorowym dorobkiem, owocem tworozego 1 przetwórozego mysizku niezliczonych pokoleñn ${ }^{2}$. Kultura pismiennicza ksiazk1 par raflalnej obefmuje doswiadczente 1 osiagnięoia srodowisks kleru parafialnego wakresie tredyoj1 kancelaryjnej, na która składa sie formuzowanie tresci zapiau oraz postá zewnetrana dokumentu piśmienniozego jako przekánika myśl1 od autora do odbiorcy.

Analiza ksiag parafialnjch powstalyoh warszawie pierwszej pozowy XVII w. 1 poznanie środowlska autorón tego typu przekazó plómienniotwa umodilw1 odpowiedź ns pytanie, ozy przeniesiente do Warszawy dworu królewskiego, a wraz z nir kancelarii wradz państwowych 1 nunojatury, miazo wpzyw ne kulture wytwarzanyoh wówozas ksiag. Porb́nanie natomiast z analogiognymi ksieggami wy branych miast polskioh pozwoli stwlerdzio, ozy poziom kultury plśmlennlozej ksiazki parafialnej warszawie byz ozyms wyjatkowym, czy te山 nie odbiegal od przeciętnej oraz w jakim stopniu zalezal on od tradyoj1 kaltywowanef w danym srodowisku, a wakim od osobistjoh uzdolnleń 1 zangazowania bezpośrednich twórór ksiazki: piaarzy 1 introligatorón.

Artykul ten stenow1 sprawozdanie z dotychczas przeprowadzomych badak nad ksiazka metrykalna powstaka w paraflach rzymsko-katoliokich ${ }^{3}$, nie upowazniajaoyoh jeszoze do peznej odpowiedz1 ns powyższe pytania, syznalizujacych tylko kierunek biezgcych 1 zamierzonjch prac.

W plerwszej pozowie XVII w. na terenie Warszawy prowadzizy dziaxalnośs trzy parafie miejakio: 
1/ parafia przy koślele kolegiackim ów. Jana Chrzciciela w Starej Warszanie,

2/ parafia koścloka Najówiętszej Maril Panny w Nowej Warszawie,

3/ parafia kościoła š. Krzyża, erygowana w 1626 r. przy Przedmiesclu Czersikim /obecnie Krakowskim/; 1 grudnia 1653 r. parafia ta mraz z kosciolem zostala przekazana XX Misjonarzom, sprowadzonym w 1651 r。 z Francfi przez królowa Ludwike Marlę 4.

W Kośclele katoliokim od dawna obowiazywal tzw, osobowy przymus parafialny. Polegal on na ryłacznośol kó́ciola parafialnego $w$ zakresie udzielania sakramentów wiernym zamieszkałym na terenie parafii. Obowiazek splsywanla udzielanych przez parafie sakramentów ohrztu 1 ślubu zostal wprowadzony w Polsce przez synoay w latach 1579-1602 jako konsekwencja przyjęcia przez duchowleństwo polskie uchwal soboru trydenckiego ${ }^{5}$. Zarządzenia synodalne podkreslały konjecznó́ć prowadzenia odrębnych dwóch seri1 rejestrów: ksiegs ochrzczonych 1 ksigg poślubionych ${ }^{6}$.

W staromiejskiej parafil $\mathbf{6}$. Jana zachowało się plęc ksiag ochrzczonych, zawierających wpisy z lat 1584-1659 z luka na lata 1626-1631 oraz dwie ksieggi poślubionych z lat 1583-1647. Z parafi1 św. Kryyza ocalały wszystkie księgi: dwie księg1 chrztow z rejestrami z lat 1626-1666 oraz jedna księga slubów z lat 1626-1657". Wszystkie natomiast księgi metrykalne z parafil NhP spłonęly w czam sie II wojny ́rwiatowej.

\section{Pozlom techniczny}

1 estetyouny warszawskioh ksiag metrykalnyoh

Isięgi metrykal ne parafil 6́. Jana posiadaja dwa formaty. Jeden to format abliżony do formatu octavo o wymiaraoh 18,5-19,5x 14,5-15,5 cm. W tym formacie sporzqajono trzy księg1 ohrztó z lat 1584-1601 i 1632-1649 oraz obie zachowane księgi ślubóm. Pozostałe dwie ksieg ochrzozonych z lat 1602-1615 i 1649-1659 maja format wydzuzony wostacl staropolskiej dutk1 sadowej o wym. 31$32 \times 9,5-10$ om. Analogiczny wymlar mają obie księgi chrztóm i księga ślubów z paraf11 ówlętokrzysklej.

Format kslęgi nie Iimitował jej objętosc1. Księgi formatu ootavo maja od 150 do 200 kart. Podobnie ksiegi dutki od 65 do 160 kart. Na og61 ksiegl oohrzczonych parafil swlętojankkiej zestam wiano ze składek 8-kartkowych nie licz̧o pierwszej składki, która 
zazwyczaj liczy 4 lub 6 kart. Natomiast ksiegi pólubionyoh obu parafil zszywano ze skzadek 6, 81 10-kartkowyoh. Przy tym 7 ks1ęgach f́iętokrzjakioh znajduja sle składki zdekompletowane przez พycięcie kart, zapewne przed zaplaanlem, gdyz 1ch brak nie zakłóca kolejnobol chronologloznej vpisów.

Księgi parafil $\mathbf{s}$. Jana sporzadzone są z papleru o róznej prowentencji. Dwie najwozed́niejsze kslęgi chrztó zloźono z papleru poohodzacego z jednej czerpalni podkrakovsklej, nosza bowiem analogiczny, choć nieoo różlaoy się znak wodny, przedstawiajacy herb Jelita: jeden na tarozy zwiehozonej korona, drugl na barokowym kartuszu ${ }^{8}$. Trzecia z zsohowanych ksiagg oohrzczonych z mpisam1 z lat 1632-1639 wykonano az z trzech gatunków papleru; jeden z wyobrazeniem orka w koronle wskazuje na papiernie w 0lkuszu", dwa puzostale maja znaki słabo ozytelno. Papier ozwartej ksiegl z filfgranem przestawlajaoym dwugzowego orła pochodz1 a podkrakowskiej papierni Tęczyńskich ${ }^{10}$, pląte f natomiast - z mayna wrocławskiego, na co wskazuje znak woday $w$ postaci litery $W$ zwienozonej koronz ${ }^{11}$. Swiętojanskle księgi oohrzczonyoh sa sporządzone z papieru sređniej grubośl, gladkiego 1 na ogó lepszej Jakośl ní te, do których wpisywano rejestry poślubionych.

Obie zaohowane księg1 ślubów maja papier gruby 1 chropowaty. Plerwsza z nich zawierajaca wp1sy z lat 1583-1620, sporządona jest z papieru czerpalni Cyatersów z Moglxy lub Jedrzejowa, poslada on bowlem flligran przedatawiaja.y w plerícieniu herb Habdank na tarczy nakrytej infuła 1 pestorakem ${ }^{12}$. Natomiast druga ksiega złozona jest z trzeoh gatunkó papieru, podobnle jak z tego samego okresu księga chrztóm; pierwsza partia papleru ze znakiem modnym postaoi dzika pochodz1 zapewne z papierni blaskiego Swidni$\mathrm{ka}^{13}$, druga - z podkrakowskiej ozerpalnf Tęozyniskich; jej znak wodny przedstawia na barokowej tarczy herb Topor z orlem w klejnocie ${ }^{14}$. Te dwa gatunki papieru rozdziela jedno bifolium z papieru olenkiego 1 gzadkiego z 11l1granem w postaol krzyza w plerśleniu o dw6ch przeolwleglyoh biegunach zakończonyoh lukiem, zwanym óli grzbiet; nad jednym $z$ ntch widnieje zarys litery $W / 4$ ?/ ${ }^{15}$. Analogioznte 1 w parafil ́́w. Krzyza sporzadzano ks1egi metrykalne z róngego papieru. Pierwsza księga obrutót zkoźna jest z czterech gatunków papieru. Podstawowa partie stanowi tu pepier polski z fillgranem przedstawiajaojm herb kodzia na mazej, renesansowej tarczyl6. Skladk1 tej kalegl rozdzlela kilks bifoliow z 
papleru o róknej proweniencj1. Jeden $z$ nich ze znakiem wodnym z wyobrazeniem Iwa na gotyoklej tarozy zwlexozonej korona poohow dz1 zapewne a czerpalni niemieoklej 17 . Pozostaze - zostazy wyprodukorane we Wrockamiu, o czym ́́,iadczy zarbwno 1111gran z rysunkiem glowy Jans Ewangelisty na renesansowe tarozy $^{1.0}$, jak 1 a IItera W wieńozong korona. Natomiast rejestry slub́́ tejze parafil wisano do księg1 wyonanej caxosol z pepleru importowanego; jego znak wodny przedstawia elenenty roblinne w plersoleniu, nad kt orym znajduje się zarys litery $\mathrm{R}^{19}$.

Stan zaohowania kslag metrykalnych parafil sw. Jana jegt zdecydowanle zly 1 wymage szybliej interwenoli konserwatorskiej. Hazystkie kslegit nosza flady zaolokbw, plam a blota, uszkodzeń mechanioznych, a nawet opalenia. Blok1 ksiag sa poryirwane z grzblet6w, a niektóre karty porozrywane. Najbardziej znisgczona jest najataraza ksiegz ochrzozonych, pozbawlona oprewy, karty tytuxowej oraz pięciu pierwsyoh kart z misami. Wraystkie ksiegi swiętojańskle byzy ponownie oprawlane, na co wakazuje przyolęole kart, niekledy wraz z tekstem. Dano Im oprawe pózakórkowa, a okładziny z tektury oblepiono brunstnym /obecnie/ paplerem. Dokonano tego zapewne $\mathrm{TIX}$. daja naklejke, na której znajduje sie aporządzony XIX-Wiecznz ręka laolński tytuz kslegi 1 daty skrajne wp1s6w. Jedynym zachowanym sladem plerwotnej oprewy wydaje sle by d zachowany pergeminowy grzbiet 1 Iragment spodniej okładki kslęg1 ochrzczonych z lat 16401649. Dlatego z dutym prawdopodobieństwem mozna sadzí, ze wsystkie księg1 metrykalne paraf11 6w. Jana oprawlano w Interegujacym nas okreste $w$ perganin.

Dwie ostatnie księi chrztó parafli ́wietojańsklej zaopatrzone zostały XVII wieku $w$ aneksy. Zavieraja one splsy ochrzczonyoh w ukxadzie miesięoznym, sporzadzone na ręoznie wylconanych formularzach ${ }^{20}$.

Księg1 metrykalne parafii \&́w. Krzyża wyszyy z kataklizmów dziejoryoh nieco lepszym stanie. I one posiadaja flady w1lgoci, uszkodzeń mechaniozny ch 1 zuajola, ale ksiega slubów posiada dotychozas współozesna okładke z pergaminu barwionego na ź́xto 1 mszystkie karty. Bardzlej zniszozona jest ksiegga rejestrow chrztow, gdzie brak karty tytukowej 1 kilku pierwszych bifolibw. Księga ta zostaza ponownie oprawiona pózskórek.

Ksiegl metrykalne obu parafil nie byzy pierwotnie followane ani paginowane. Spotyka sle natomiast - ohoó bardzo rzadko stosowa- 
ne - kustogze wrrazowe. W XIX wieku, ozasie przeprowadzania akoj1 inventaryzacyjnej, ks leggi ániętojańkie zostaxy spaginowane, a kglęg1 świętokruskie sfoliowane, przy ozym numeraoja objęra tylko karty z wpisami metrykalnymi.

Najwoześlej stosowanym ukzadem grafloznym ksiag metrykalnyoh parafi1 d́w. Jana jest jedna kolumna pisma, obejmujaca zazwyozaj równlez 1 prawy margines. Często na górnym marglnesie wplsywano date roozna lub nazwe miesiaca. Kolumne pisma rozdzielaja pisane wékszymi literami daty poszczeg6lnych rejestró lub data rozpoczynajaos nowy rok. 0d 1632 r. zastosowano bardzief przefrzysty układ: kolumne wpis6w zawezzono 1 na lewym poszerzonym marginesie wpisywano dzień 1 miesiac rejestru. Stopniowe przechodzenie do bardziej raojonalnego sposobu zapisu moźna zaobserwowad $w$ ksıędze blubów z lat 1621-1647; w latach 1621-1625 stosowano jedng kolumne plsma rozdzlelona datami wpisó, od 1626 r. rozpoczynano wplay od loh datacjl, by wońcu od roka 1632 wyrzuoá datę na lewy margines.

Forme bardziej nowoczesnego zapisu w prowadzeniu kg1ag metrykalnyoh zastosomala parafia sw. Kroyza. Juz - 1626 r. mazystkie ksjęg1 sa tu prowadzone metoda, ltóra w parafil $\mathrm{s}$. Jana przy Jęto doplero 1632 r. Odstęptwem od tej zasady вq rejestry kstę ich datacj1 jednej kolumnie plsma. Wszygtkie ksiegi fwiętokrzyskie az prowadzone dosc starannie, ale bez specjalnej trosk1 o Ich ozdablante.

Prym w zdobieniu kgiag metrykalnyoh wiedzie parafia swiętojańska. Tytuz ksiegi "Liber bapt1satorum" kreslono zazwyozaj antykwa, pozostaly tekst kaligrafiozna 1talika. Do najbardziej ozdobnyoh nalezy karta tytuzowa ks legi ochrzozonych z wpisami z lat 1602-1615. Jest ona wykonana ozarnym i czerwonym atramentem, przy czym litera $I$ skowie "LIber" jest wycreslona $p$ formie Inicjaxu ze zdobleniant ró́linnymi. Na uwage zasxuguje równiez karta tytułowa kslegg1 chrztó z lat 1640-1649. Tytuz romieszczony tu zostal na calej powlerzchni karty przy zastosowaniu gradacji liter. Majbardziej wazkie - zdantem wykonawcy tytuzu - słowa "Iiber baptisatorum comparatus - - per me Adamum a Slopsko - -" wykreslono antykwa. Niejednokrotnie równie starannie 1 ozdobnte rozpoczynano nowy rok wplsow, przy ozym nlekledy stosowano ornamenty roslinne 1 wategowe, uzymajac takio atramentu czerwonego ${ }^{21}$. 
Tego typu dekoraoyjne karty tytukowe 1 ozdobne rozpoozynanie nowego roku mpls6w wykonywano w zagadzie tylko w ksiggach o chrzczonych. Nadmierna jednak troska o plekno karty tyturowej doprowadziza do pozbawien1a tytuzu ksiege ohrztu z lat 1632-1639, gdzie dwie karty plerwszej skladki do da1́́ śwleca pustka. Zdobienie ksiag nie zaozyło sle jednak z dbałoscla o estetyozny wyglad calej ksiegi. Pisano na prizemian raz czytelnie 1 starannie, to znowu niedbale $z$ przekresleniami 1 kleksamt.

Kadda z omawianych ksiag zawiera wplay wielu rqk. Sq one wykonane zarówno p16́rem szeroko sciętym, jak 1 ostro zakonozonym, przy uzyciu atramentu o róznym skzadzie chemicznym. Swiadczy o tym stan zachowania pisma: jeden wpls jest zachowany doskonale, drugi obok splowlazy, inny w sqsiedztwie rozmazany. Plsano wtedy kursywa olresu przejśclowego ${ }^{22}$, gdy plsmo gotyckie powoll przekaztałcało ste $w$ renesansowo-barokowe. Jest ono przy tym bardzo zindywidualizowane, zazwyczaj krélone swobodnie 1 z duzym rozmachem. Charakterystyczne sa tu duze Iltery $\mathbb{R}, \mathbf{K}, I$; 1 ch dolne kresk1 sięgaja poza linie wiersza, obejmujac półkolem kilka liter wyrazu. Typowe jest takie zaopatryanie lasek liter $p$ i $q$ dodatkowe nasadif, pochylone w lewo. Stosuje ale okragle s przy stopniowym zanikantu s prostego; górne laski liter d, $h$ i k sa wywinlęte w prawo; uzywa się także unojalnego d z tendencja do przedıuzenia gornej kreseczki dla połaczenia z następna litera. Plsmo większosc1 wpisow jest poohylone w prawo, a litery w wyrazie czéściowo połaczone. W latach 1583-1620 stosowano bardzo duzo skrótów, potem Ich 1ló́ć się zmniejsza. Na uwagę zasługuja wpisy z roku 1601 w księdze chrztón parafil fw. Jana, wykonane kaligraficzna 1tal1$\mathrm{ka}^{23}$.

Obowiazujacym Językiem wplsow metrykalnych był język kacińsk1. We wszystkich jednak księgach obu parafi1 moina spotkać słowa polskie. Okré́lano nlekiedy w języku polskim zawód uczestnika ceremonil kosolelnej, taki jak bednars, kapelusnik, siodlarka, ksiaznik, kramars oraz nazwj mlast 1 ulic, np. platea Dluga, Koszia. Zdarza się rówiez cytowanie typowo polskiejwersji imion własnych, jak np. Maryna. Od polonizmow wolne sa tylko wplsy francuskich księży Misjonarzy. 


\section{Metoda zapisu rejestru metrykalnego}

Postanowienia synadalne zobowlazywały polski kler parafialny do systematycznego rejestrowania udzlelanyoh chrztów 1 slubow, wymieniajacc niezbędre elementy zapisu. Zostazy one ostateoznie sformułowane $w$ Iiscle pasterskim prymasa Bernarda Maciejowskiego w 1607 rokn $^{24}$. Rejestr ohrztu miax zawierá rok, dzień i miesizo obrzędu; 1mie, nazwisko 1 stanowisko koślelne kaplena udzielajacego sakramentu oraz personalia rodziców 1 chrzestnych. Natomiast zapıs §lubu - prócz daty obrzędu i danych okrélajacych kapłana - personalia nowotehoów, miejsce obrzędu, „miona 1 nazwiska f́ladków oraz wiadomose o ogłoszeniu zapowiedzi. Wprowadzono wówczas do rejestraoji metrykalnej stylizacje sublektywnq.

Analizowane księg1 metrykalne $w$ zasadzle spe rnialy polecenia wadz kosolelnyoh.

Poszczególne wp1sy sq dokonywane w obręb1e roku, którego początek jest zeznaozany niekiedy w sposób uroczysty ${ }^{25}$. Dzlé 1 miesląc obrzędu zaplsywano cyfra 1 nazwa miesia og lub té wyrazano wg kalendarza kościelnego przez okreslenie dnia w stosunku do śrięta kó́cielnego. Niekledy, jak to ma miejsoe wsiegroh świętokrzysskich, poszczególne wpisy rozdzielano nazwa miesiaca, rejestrująo w zapisie tylko kolejny dzień. I tu, w parafil $\mathbf{6}$. Krzyza nie spotyka sle w zasadzle obronologicznego przemieszania upiśt; sa natomiast rejestry uzupe nniajace, sporzadzone na kartkach wklejany ih do ksiag pod odpowiednia data lub wplsane na kartaoh oohronnyoh. Inaczej bywazo parefif śletojańskiej. Mozina tu spotkac part1e wp1s 6 datowany oh formuła weodem die", co budzi watplimoś w wary godnof́ takiej datacj1. Zdarza się równie przemieszane chronologloznle $\mathrm{l}^{26}$ lub ogole nie zarejegtrowane 27. Dlatego nasuwa sie przy puszozenie, ze plerwotnle nie zawsze precyzyjnie datowana rejestraoja udzlelanyoh sakramentó by dokonywana na luźnych kartkach, które pónflej nie uporzadkowane chronologicznie przeplsywano do ksisg. W obu parafiach rezermowano na takie uzupełniajace wpisy czésol stron lub oałe karty ${ }^{28}$.

Poczatek wpisu ohrztu formulowano w sposob nastepująoy: "Ego - - baptisari" lub tez "Baptiaatus est - -" Obok spotyka sie nietypowy sposరb rejestru, np. "Lavatus est puer e fonte saoro - per me Andream Dluanievitha"29, "Sacram Baptismam susoepit infans 
- - per me Laurentium a Zakroozimn30 Iub tez "Saoramento baptisma11 initiata est - - per me Andream Lano" oraz "In lavacro solutis est la[ra] ta foemella - - 31 . Tego typu sformulowanta, nie zmieniajac wartosol wpisu, swladoza o inwenoji autora rejestru.

Niekiedy jednak przy stosowaniu stylizaoji obiektymnef opuszczano personalis kapłana, ograniczajac sle do imienia ochrzczonego. Okré́lano go słowam1 puer, Infans, puer masculus lub masoulint sexus, foemella lub puer sexus foeminei, a takie fillus 1 1111a. Zazwyozaj jednak plec ochrzozonego jest określana poprzez nadawane mu imię.

Następny element rejestru chrztu to imiona rodziców 1 nazwisko ojoa, często z okresleniem rangi społeoznej, urzędu lub zamodu oraz miejsca zamieszkania. W analoglczny sposób cytowano personalia rodzicó chrzestnyoh. Przy tym range spoleozna wyraźano słowami: Lamatus, honestus, nob1l1s, 1llustris, generosus, reverendus itp.

Z chwila ogłoszenla przez dziekana parafil ów. Jana rozporządzenia o obowiazku informowanla, ozy dzlecko jest zrodzone z

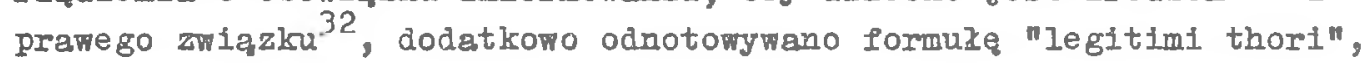
"1lilgitimi" lub tez "legitimorum parentum", "ooniugls legitimae".

Czestokroc, w zalezinosol od pozyoj1 sporecznej rodziców dziecka, dokonywano wisu rozwinietego lub skróconego do mimimum. Typowa forma skróonego zapisu chrztu brzmi: "Baptisatus est puer nomine Hedvigis, pater elus famatus Martinus bibliopola, mater Dorothea. Levantes famatus Paulus bibliopola cum Anna B1goszowan ${ }^{33}$ lub "Ego Joannes Lydzbarski vioarius baptisav1 Helisabetham Lucae Cleti, impressoris librum et Catharinae. Patrint Julius Ginter et Helizabeth Herlerowa uxor musioi SBMn34. Przykładem zá rozwiniętego rejestru jest wpis chrztu dziecka Piotra Elerta, zarejestrowany w paraf1i św. Jana pod data 22 III 1648: "IIlustris et adm[odum] rever[endus] dom [inus] Adamus Alezander Alans, praepositus Varsar [iensis]], baptisavit Josephum domini Petri Elert, typographi SFM ac civis Varsaviensis et Elisabethae, con[iugis] leg[itimae]. Leventes fuerunt magniflous ac generosus dominus Alexander de Iubomlerz Lubomiersk1, supremus stabuli praefectus regni cum domina Catharina, oonsorte legitime nobilis Philippi Huttiw, notaril decretorum SRH ${ }^{35}$.

Zdarza sie jednak, ze rejestr chrztu nie zostal ukońozony. Wpisano tylko imle dziecke 1 np. tylko imione rodziów bez poda- 
nia nazwiska ojca 1 rodziobw ohrzestnych. Tego typu zapisy spotyka się $w$ księgach úwiętojańskich ${ }^{36}$.

Podobnie jak chrzty, rejestry §lubbw zapisywano cji subiektywnej lub oblektywnej. W pelnym wpisie przy okreslaniu personaliów nowozeńców podawano madomóś o przeprowadzonym dowodzle stanu cywilnego 1 stopniu ewentualnego pokrewieństwa oraz ogłoszeniu zapowiedzi. Zaznaczano równiez mlejsce ceremonil, zwaszcza wtedy, gdy odby $a$ się ona w domu prywatnym lub w innym niz parafialny kofcielè. Przykładem takiego wpisu jest rejestr şubu Hiacynta Filipowicza z 20 II 1650 r.: nEodem die ex admissione me1 hebdomadaril r [everendus] p [ater] Albertus Mazurkowio vioarius ex speciali consensu per[1Ilu]stris d[omíni sigismund a Chyzow Chyzowsit, Plocensis et Varsaviensis canonict, SHM seoretarii, in loco oft[iola]li consistoril Varsaviensis judicis surrogati, super banna et domum privatam matrimonium inter honestos Hyacinthum Philipowic introligatorem de Varsavia et Annam Matysczanka de 0lkusz, prius affinitatis consanguinitatis et allis canoniois impedimentis diligenter examinatis et non inventis, confirmavit. Praesentibus pro assistentia et huius actis ornamento congregatis 1llustri ac $r[$ evere]ndo d[omi]no Stephano Tydzga, abbato Sieciechoviense, contionatore SRM, per[illu] stri ac ad[mo]dum $r[e] v[e r e n]$ do d[omi]no Ludovico Fantini, eoc[lesiae] Coll[egiatae] oustode, SBH secretario, excelentibus d [umi] no PhIlippo Huttino, decretorum SRM notario et elusdem SBM secretario et Petro Elert, typographo ac SRM musico, tum Joanne TreIpinski, SRM typographon 37 .

Tego typu zapis nalezal do rzadkosol 1 stosowany by 1 przewaźnie przy rejestracj1 zarlubın patrycjatu warszawskiego, szlachty $i$ osób związanych z dworem krolewsklm. Zazwyczaj uźywano skrbconef formy wpisu, jak to np. miało miejsce przy rejestrze ślubu Pawła Fludzica w para 11 sw. Jana: "Ego Seraphinus Czerwonka $\nabla 1-$ carius matrimonium inter Paulum Fludzlo bibliopolam et Mariannam Daskowne, civem Varsoviensem. Praesentibus famato Melchiore Wolsk1 bibliopola Varsaviense et domino Jacobo Miesoovio plotore, etiam clve Varsoviense"38. Jeszcze bardziej skrócony rejestr stom sowała parafia sw. Krzyza, czego przykładem moźe byd zapis slubu Jana Talara z 3 III 1631 r.: "Copulati sunt Joannes Talara et Catherina, praesentibus testibus Christophorus Regenski et Albertus Rzadkowskin39. 
Podobna metode zapisu stosowano obu parafiach. Do ciekawostek jednak należy system racjonalizecji wpisów, zastosowany przez dwóch wikariuszy z paralii świętokrzyskıej, Pawla Cybulskiego 1 Adama Czegłowicza. Zarejestrowali oni pierwszy udzielony przez siebie ślub w formie pełnej, następne zaś wpisali skrócone do minimum ${ }^{40}$.

Generalnie należy stwierdzió, ze rejestry metrykalne parafil św. Jana zawieraja o wiele więcej wisów rozwintętych niz to ma miejsce w księgach świętokrzyskich. Dlatego stanowia one bezcenne źródło wiedzy o mieszkańcach owczesnej Warszawy, o wykonywam nych przez nich zawodach 1 pełnionjch funkejach oraz miejscu zamieszkania, o ich sytuacji rodzinnej, kręgra kontaktów zawodowych $i$ towarzyskich. Przykładowo zacytowano wy zej kilka rejestrow dotyozących pracownikbow ksiażki.

Księgi swiętojańskie sq ponadto swego rodzaju kronika klęsk elementarnych. Rejestrowane sa tu bowiem informacje o zarazach nawiedzających Warszawę oraz wiadomości o przebiegu działań wojennych, kt6re bez wątpienia w dużym stopniu utrudniały prowadzenie pracy duszpasterskiej na terenie paraf11 41 .

\section{Pisarze ksiag metrykalnych}

Jak wyżej wspomniano, parafia 6́⿴. Jana usytuowana by la przy koleglacie 42 , kościele o najwyzszej randze $w$ arohidiakonacie war szawskim ${ }^{43}$. W skład kapituły kolegiackiej, obok prałatón 1 kanoników oraz pewnej liczby duchowleństwa nizszego, wchodzil archidiam kon; tu rónnież miesoiła się siedziba oflojała generalnego z konsystorzem. Głowa kap1tuły był dziekan. Jemu tez podlegal zarząd kościoła śr. Jana i rządy duszpasterskie paraf11. Peln1ł je przy pomooy wikarluszy, angazowanyoh na podstawie umowy 1 utrzymywar nych z prowizji płaconej z częśc1 beneficjum dalekgńskiego 44 .

Zachowane metryki świętojańskie pozwalaja stwierdzić, ze duszpasterstwem w zakresie udzielania chrztóm 1 álubów zajmowali sie prawie wyłacanie wikariusze ${ }^{45}$. Do nich tez nalezało prowadzenie rejestrów udzlelanyoh sakramentóm. Nosili onl przewainie tytul "adminlstrator sacramentorum", co było równoznaczne z pełnieniem przez nich obowiazk6w proboszcza parafil w czasie jego nieobeoności. Niektorzy mikarlusze parafi1 sw. Jana używal1 tytułu "vicarius perpetuus". Czasem wikariuszy zastępowall mansjonarze, altaryści i psazterzyśc1 46 . 
Autorstwo poszozegolnyoh wp186m metrykalnyoh $w$ paral11 swietojańskief jest trudne do ustalenia. Nle rawsze vladomo, kto sporzada1l tekat rejestru, a kto ten rejestr mplsal do ksiakki. Sprewa jest prosta, gdy zapis sformulowany jest w stylizaojl subiektywnej 1 podplsany przez wikariusza jego imieniem 1 nazwiskiem z dodaniem formuzki "subsoripsit manu propria" / skróole "ss mp"/. Hie ulega równiez watpliwosoi autorstwo tekstu zaplsu w wadku, gdy kapkan wyientony " rejestrze jako vicarius hebdomadarius" aøystuje przy ceremonil dokonywanej przez wyżzego ranga duchownөgo, np. kanonika lub blskupa. Zdarza się jodnak, ze rojestry podplsane przez róngych wikariuszy wpisane zostaly do ksiegi przez jeana osobe ${ }^{47}$. Zapewne podpis wikariusza potwierdzal wiarygodnos zaplsu, co oczywí́cle nie znaczy, te byz on równiez autorem tekstu. Nieco inaczej wygleqdaka sytuacja, o której notatke wpisal między rejestrami sam wikariusz: "Anno Domini 16533 Aprilis ego Stam nislaus Wadaczewskl, eccl[esiae] coll[egiatae] S.Joannis Baptistae Varsov[iensig] Vicarius perpetuus, haec matrimonia oollegi et ea hunc 11 brum metrioes copulatorum inscripsin 48 .

Dlatego mokna z duźym pramdopodobieństwem przyjać, źe autoram1 1 plsarzaml rejestrów byl1 wszysoy udzlelajaoy aakramentow lub towarzy azcy ceremonil wikariusze 1 zastępujaoy ich niekiedy manajonarze, altarýci 1 psałterzysoi.

Sprawa jest mnlej skomplikovana, jesli chodzl o mloda 1 wtedj jeszoze mniej atrakoyjnz parafię sw. Krzyza. Występujaoy w księgach metrykalnych paraflanie to przede wazystkim drobni mieszczanie, czasem słuzba dworb szlacheckioh. Wszysoy bowiem zamoźniejsi mieszkańcy tej parafil, w tym oczymície magnaci, korzysta11 z usług kolegiaty. W parafii 6́riętokrzyskiej przez kilka lat duszpasterstwem zajmowal się przewaznie jeden wikartusz, rzadko w towarzystwie proboszcza para11149. Zarbwno stylizacja wpisu, jak i charakter pisma pozwala sqdaib, ze kapłan udzielajaoy sakramentu by 1 jednocześnie autorem 1 pisarzem rejegtru. Inaczej wygladazo to

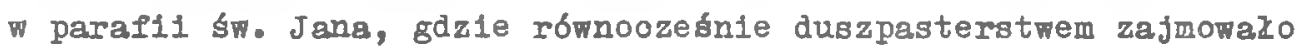
się kilku lub kllkunastu wikariuszy.

Pozlom zaplsu - jak wiemy - nie jegt rowny. Jego bardziej lub mnlej rozwinlęta forme między Innymi zaleźała od pozycj1 spoIecznej ohrzczonego lub poślublanego 1 zapewne by za zwiazana z wysokosila złozonej ofiary. Ale samo sformulowante rejestru, jego styl 1 uzyte słowniotwo śwladozy o wyksztalceniu autorow wp1sbw, 
- 1ch znajomócl realióv ówozesnego zucla spolecznego 1 polityoznego. Znane sa w Itteraturze opinie o niskim poziomis moralnjm i unyskowym klemu parafia nego tego okresu ${ }^{50}$. Wydaje sle jednak, ze przynajmntej ntektórzy z w1karluszy obu parafil miel1 w1ększe przygotowanie do pexulonia powierzonych lm funkcji njz to się powszechnie głos1. Do takich nalezaloby zaliozýd przede wszystkim wikariuszy, który pejnili foukoje wioedziekana, a więc Jana z Garwolina, Andrzeja z Diuzniewa ${ }^{51}$, Jana z Czarnowa, Jana Mikozajowicza I Adama ze Stopska. Do tej grupy nalezy takze dozaozý zam stępob' kustosma kepitury koleglackiej: Andrgeja z Blonla, Andrzeja lazurkowieza, Jaua Mlezdzińskiego, Jana z Zakroczymia, Serafina z Jasieńca, Stanibzama Inochowkisgo, Stelana Pozdziesz i Alberta z Cielgdza. Ne unage zasługuje rbwniez Stefan Zaręba, ktory byz notariuszem oflojaka warszawslego, Staniszaw Jan Kanty Wada ozewski, bakalar sztuk wyzwolonyoh 1 fllozofil oraz rektor szkozy 8. Dracha, a takze Wawrzyniec z Zabroczymia 1 Andrzoj z Lequyna, autorzy nietypowyob rejegtrow oraz z parafii 6. Krzy za wikarIusze "racjonalizatorzy" - Pawez Cybulght 1 sdam Czeglowioz.

Dalsze badania nad struktura spoleczna 1 wyksztaxoeniem duszpasterzy warszawakich parafil pozwola dokladniej sprecyzować $1 \mathrm{ch}$ mkład w kstaxtowanie isfiackl pareflaldej. Forómnanle natomiast warszawskloh rejestróm pararialnych z ks1ęgami metrykalnymi Poznania, gdzie miéfolła się radza kobclelna Wargzany, Krakowa - dawnej stolicy i siedziby dworu królewskiego oraz lublina - miasta sejmbw umozliwi Loh ocene na tle bmoregnej kultury kancelaryjnej parafii miejakich.

Aneks I

Wylcaz wargaswion kgias metrykalnych z lat 1600-1655

Parafia 6́w. Jana Chruciclela

IBJ 1 iac. i pol。 17 VI $1584-28 \times 1601.19,5 \times 14,5$ cm. S。 350. P1smo wielu rak. Opr. calkowicie zniszozone. Księga oohrzozonyoh kokolele kolegiaokim sw. Jana Chrzc1ciela Wars Brak $k$. tytuzowej 1 plexwszyoh plęclu z wpisam metrykalnyni.

Znak wodny: herb Jelite ne barokowej terczy, zweńozonej korona. SlniarskamCaaplioka 364. 
IBI 2 Hac. 1 pol. 22 VI 1602 - 14 II 1615. 32 × 9,5 cm. X. I. nIb S.256.

Pismo w1elu rak. Opr. pzsk. IIX "Ilber baptisatorum comparatus per ne Joannem Clarnowsk1 vicedeoanum ecolestae collegiatae Varschoulensis. hano Domini $1602 \%$.

Znak wodny: herb Jelita na barokowym kartuszu. SiniarskeCzapI1cke $383,388$.

IBJ 3 /1615-1632/ kstegga zaglnąa w czasie II wojny światowej.

IBJ 4 uac. 1 poI. 2 III $1632-27$ XII 1639. 18,5 x 15,5 cm. K.2 nIb S.300 K.2 nlb. Pismo wielu rak. Opr. pIsk. XIX w. Księg ochrzczonych kosciele koleglackim ́́w. Jana Chrzciciela Warszawie, załozona 1632 r。

Brak tytułu.

Znak wodny: orzel w koronie. Siniarska-Czapl1oka 771, 772. Dwa inne filigrany nleczytelne.

IBJ 5 Eac. i pol. 1 I 1640 - 12 IV 1649. 19 × 15,5 cm. K. 3 nlb S. 390 K. 14 nlb. Pismo wielu rąk. Opr. pergamin częściowo zachowana, uzupe Łniona XIX w.

"Liber baptisatorum comparatus per me Adamum a Slopsko protunc vicedecanum eoclesiae collegiatae s. Joannis Baptistae Varsauiensis. Anno Domin1 1640".

$\mathrm{Na} k$. tytułowej imie 1 miejsce pochodzenia kapłana oraz słowo "vice" wpisano po starciu poprzednio umieszozonych tu sæóm.

Znak modny: dwugłowy orzez. Siniarska-Czaplicka 1137-1141. K. 1-14 nlb zawieraja wykaz oohrzczonych w ukiadzle miesięcznym na ręcznie wykréslonym formularzu. P1smo XVIII w. jedne $\mathrm{reqki}$.

Znak wodny: tarcza zwieńczona korona z herbem Gdańska, podtrzymywanym przez dwa Iwy. Sinlarska-Czaplicka 196.

LBJ 6 Iac. 1 pol. 21 IV 1649 - 26 III 1659. 31 x 9,5 cm. K.2 nlb S $316 \mathrm{~K} .18 \mathrm{nlb.} \mathrm{Pismo} \mathrm{w1elu} \mathrm{rak.} \mathrm{Opr.} \mathrm{płsk.} \mathrm{XIX}$. "IHS Liber baptisatorum pro ecclesia colleglata sancti Joannis Baptistae Varsaulensis. Ab anno 1649. Per me Joannem Lydzbarski vicarium et protunc procuratorem unitis collegij vicariorum oomparatus". 
Znak modny: litera W zwieńozona korona. Maleczyńska, ryc. 19.

K. 1-18 nlb zawieraja wykaz oohrzozonych zatytulowany: "Cathalogus baptisatorum. In hoc libro descriptorum pro faciliori modo quaerentium concinnato". Pismo XVIII w. jednej ręki.

Znak wodny: fragment górnej partil, przedstawlajacy orła nad tarczą. Może papiernia Tęczyńskich? Siniarska-Czaplicka 1123.

LMJ 1 Eac. $i$ pol. 15 V 1583 - 29 XI 1620, 19 x 14,5 cm. K. 3 nIb S 312. Pismo wielu rak. Opr. pIsk. XIX W.

"Anno 1583 mense aprili. Incipit liber matrimoniorum ex decretas cono1lii Tridentini, sesione 24, cap[itulo] de reform [atione]". K.3 r zawiera tytur ksiegi, pod nim wpisano rozporzadzenie: "Habeat parochus IIbrum in quo coniuctum et testium nomina diemque et locum contracti matrimonil describat quem diligenter apud se custodiat".

K. I zachowana szozatkowo, 2. r z napisem u góry: Matrimonium est viri et mulieris coniuctis inviduam vitae societatem continentio". Pod nim sentencja: "Quos Deus coniunxit, homo non separet".

Znak wodny: T plersoieniu herb Habdank, nakryty infula 1 pastorałem. Sinlarska-Czaplioka 271.

IMJ 2 Eac. 1 pol. 10 I 1621 - 9 VII 1647. 19,5 x 15 cm. S. 300. Pismo wielu rak Opr. płsk. XIX w.

Księga poślubionych w kościele kolegiackim sw. Jana Chrzciciela warszawie zaprowadzona w 1621 r.

Znaki wodne: postac dzika. Badeckl 23; krzyz w pierścieniu - dwóch przecimległych biegunach, zakończonyoh łukiem zw. oǵli grzbiet, nad jednym z nich zarys litery W/M ?/; na barokowe tarczy herb Topór z orzem $w$ klejnooje. SiniarskaCzaplicka 1123, 1125.

IMJ 3 /26 VII 1647 - 27 XI 1672. S. 422/ Ksiega zaginęa po 1945 r. Maszynopis ksieg1, odczytanej przez J.Turgka-Straszewska, znajduje się w Arch. Archidiecezjalnym w Warszawie. 
Arohiwum XX Misjonarzy Trakon1e

LBC I tao. 1 pol. 28 VII 1627 - 23 XII 1648. 31 x 10 cm. K. 2 nlb, 71, 2 alb. P1smo wielu rak。 0pr. plsk. XIX w.

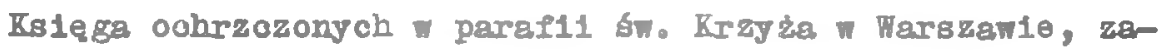
prowadzong $1626 x$.

Brak k.tyturowej oraz $2 / ? /$ b1fol16 z wpisami z okreau od 1626 - 27 VII 1627123 XI 1627 - 10 IV 1628.

Znak1 wodne: na makej/2,5 × 2 om/ ronosensowej tarozy herb Jodele; postad Iwe na gotychlej tarczy, zwieñozonej korong. Briquet 10582-10588; glowa Jana Brangel1sty ne uproszczonej w rysunku tarozy renesensove f. Maleczyńsk, ryo. 21; l1tera Ti zwleńczona korong. Maleozyńsk,ryo. 19. Znak wodny kart oohronngch: glabo ozytelny symbol literowy - $\mathrm{X}$ I E $* / ? /$.

Na k. 7IV pod rejestrami metrykalnymi vpis: Iste liber beptisatorm oontinet nomina bapt1satorum ab anno $1627 \mathrm{~d} 1 \theta$ 28 aprilis/przekrélono "aprin 1 dopisano "poan/ usque ad annur 1648 inolustue, sed al1qua exolderunt".

Na przedostatnief k.ochronnej vpla: WRonozy GLę. Radca Heroldy1, dyreltor kanoelary 1 z poleoenla prezydy1 Heroldy1 przejrzawsy te kstatee tadnyoh proyleplonych metryk nioznalazIsøy / 10 //, miejsoa prokne Ilalami opatrayz 1 zaopatrzy awolem podplsem. II Varazaw1e $a[n i a] 8 / 20$ alerpnle 1841 r. Matuszewsici. Pod tym wpleem z lewej strony

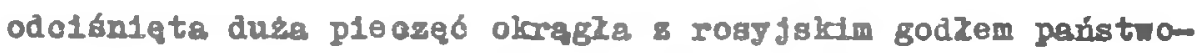
wyin 1 nleogytelava napisem $/$ otoku. Po prawej stronie podp1s: W.Xcanow1ńsk, pods[elretarg] kI[asy] II". Ke verso

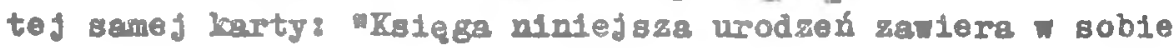
gallogbowanjoh 1 saparafowanoh 1 logbe lcart sledemdalesiat jeden, To 71. Wers [zama $]$ 1/7 [18]54\%.

LEC 2 / fac. 1 pol. 1648 - 1666/ Kalesa dotychoras nie odnaleziona

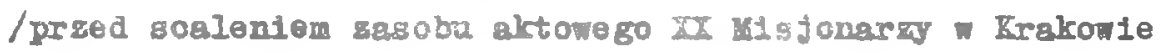
calega ta gnajdowaza ale kancelaril parafialnej 6w. Krayta $\nabla$ Warszavie/.

IMC 1 Lao. i pol. 21 IX 1626 - 14 X 1657. 31 × 10 of. K.2 nIb, 65. Pismo wielu rak. Opr. pergamin.

"Ilber matrimonialis seu matrymonialiter copulatorum ecoloBlas parochial1s sanotao Crucls in suburbio Craooulenst cl- 
V1tat1s Vargoulensis. Sub reotore elnsdem ocoleslae protuno venarab1l1 Andxes Luban10, masionario soolesiac collo-

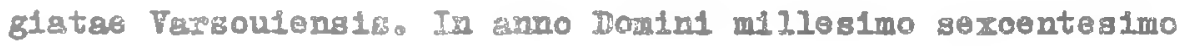
Vigesino vexto. Irsasidante tuno in eploogatu Posnasiensi 11lustrissivo et roverendissino in Christo Patre et Domino

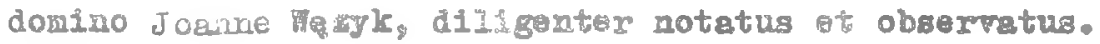
1626:

Znak wodry: elemerty rodilnne plexfoleniu, nad nin zarys litery $\mathrm{R}$.

Ha doje k. tytulows napls: Patronis et collatoribus olnsdem aoclesise ao fundatorfbus $\nabla[1]$ d $[$ [11] cet gpeotab1libus Paulo zembreusl. KJuozall ot Helena conluglbus superetiti bus".

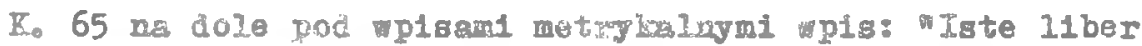
matrimonlorure coutlnet omila metrimonia oontraota in ecoleala parochisil s [anotse] Cruols Varsaulensis ab anno 1626 21 aeptembris ad anno 165714 ootobris. Jsięga niniejera szlubb sawlera goble zaltozbowanoh 1 perafowany oh $11 \mathrm{cz}$ be kart széd́dqlesiat pląó to 65. Tarsz[ava] 1/7 1854 r.".

Aneles II

Plsarge kglae tretrykalnych parafil áw. Jana Warsqawle

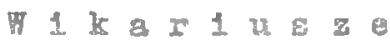

1. Sebastianus a Clechanow ...... . . . . . 1584-1598

2. Bartholomeus Flezdzinsk . . . . . . . . . 1584-1601

3. Seraphtr Jasienitius . . . . . . . . . 1584-1603

4. Juanner a Zalroczim . . . . . . . . . . 1584-1594

5. Stanislaus a Crotossin . . . . . . . . . 1584-1586

6. Josephus a Garmolin . . . . . . . . . . 1587-1597

7. Stanislaus Skrlsk ............. 1587

8. Andreas Dluznieritha .............. 1587-1601

9. Laurent1us a Zakroorim . . . . . . . . . 1588-1595

10. Sebast1anus a Moginica . . . . . . . . . 1588-1590

11. Mathias Cervinus Jelowsk1 . ........ . . 1589-1590

12. Sebastlanus Szonowsk1 .............. 1589

13. Martinus Raczulsk1 . . . . . . . . . . 1589-1590

14. Sebastianus Borzewgkd .. . . . . . . . 1589-1590

15. Andreas Grodz180 .................. 1593-1597 
16. Hioolaus a Plonst ................. 1594-1601

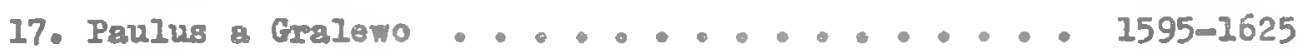
18. Stanfslaus Droohowsll ............... 1596-160I 19. Albertus Grialus .............. 1597-1598

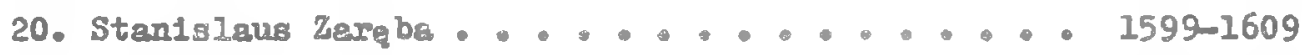

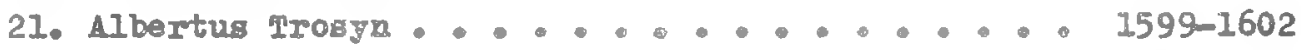
22. Joannes Zęrow ............. 1599-1611

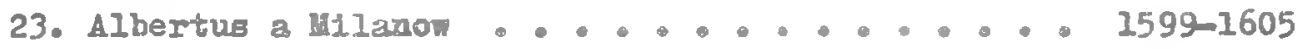
24. Joannes Pomorgk1 ............. 1600-1601 25. Joannes a Tұвs08ze .............. 1602-1626 26. Joannes Czarnowsld ............. 1602-1623 27. Stanisleus a Garwolin............... 1602-1609 28. Hathlas Grodrieor ... . . . . . . . 1603-1607

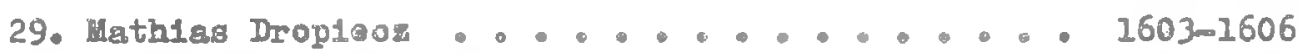
30. Stanislaus Gzernensis ............ 1603-1604 31. Andreas Blonensia .............. 1605-1655 32. Joannes Grodzi60 ............... 1605-1607 33. Andreas Iqncrinensia ............. 1606-1607

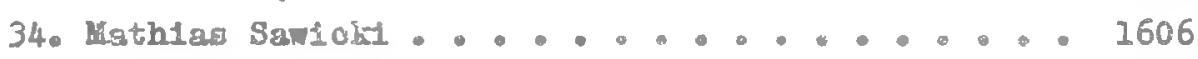

35. Hathias Sannik1 ................... 1607-1612 36. Joannes Pratnical1 ............. 1608-1611 37. Matheus Kubersk1 ................ 1608-1615 38. Bartholomeus Blonensig . . . . ..... 1609-1612 39. Jecobus de Jazgarzen ............. 1611-1512

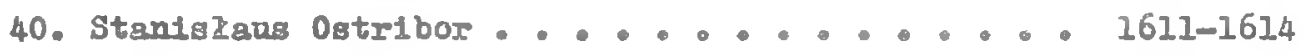
41. Adamus a Szopak ...................... 1612-1644

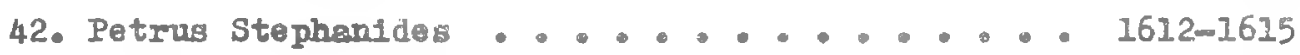

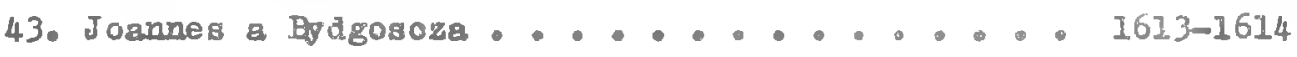
44. Joannes Debowskl ............ 1613-1615 45. Joannes a Plook ................................ 1514-1615 46. Alezander Kuczewsk1 ............. 1621 47. Jacobus Czerntevius ................ 1621-1622

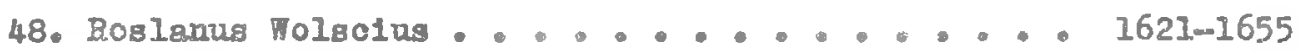
49. Stanislaus Maonorius ............. 1622-1626 50. Joannes Mikolaioricz ............ 1622-1636 51. Thomas Pa10wsk1 .............. 1626m1631 52. Joannes W1tunsk1 .............. 1628

53. Simon Msconoritha ............. 1629 54. Albertus a Czelandz .................. 1629-1655 
55. Seraphin a Grerwonka ............ 1632-1644 56. Andreas Mazuricow10z ............. 1632-1655

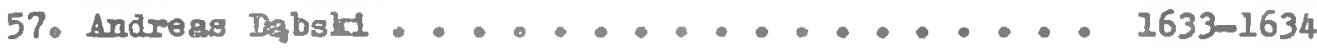
58. Mathias Biarzobrzegk1 ........... 1633-1634 59. Jacobus Zawlezowto a Gabin ........... 1638-1639

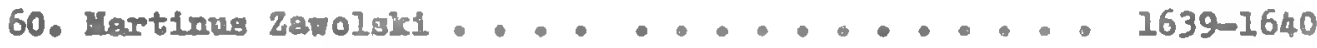
61. Adqurus Strozewsld ............. 1639-1644 62. Joannes Iydubarale1 ............. 1639-1654 63. Alexander Jastregbsl ............. 1641

64. Stan1slaus Xorjold ............. 1641-1643 65. Stephrnus Pozdr1essow10 ........... 1642-1655 66. Stanis laus Jodzowsk ............ 1643-1644 67. Mathlas Zgrankowsk1 ............ 1647-1655 68. Standslous Gantius Hadmozensid ....... 1647-1655 69. Stanislaus Mokroold ............. 1649-1650 70. Simon Iglingli ................... 1655

PBazterujéo1, masjonarge 1 altarýol

1. Andreas B1j8serithe - alt. ......... 1584-1587

2. Stanislaus a gremolin - paax. ........ 1589-1601

3. Lndreas Kalinski $1607-1615$

4. Thomss Inbersozkj -

5. Gregoriug Laohowioz -

6. Iucas chlebowioz -

7. Adamus Mirek -

8. N1colaus M1lkowski -

9. Jacobus Iozkow10 Warka -

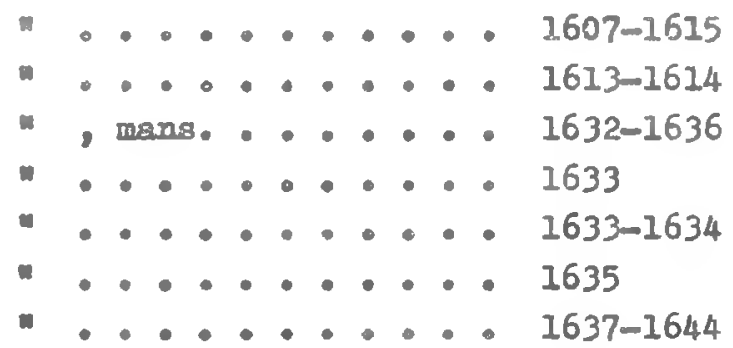

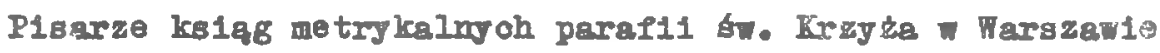

1. Paulus Cybulsir1 - vioarius .......... 1626-1630

2. Adamus Czegzowicz - " .......... 1631-1636

3. Joanneg Zajdlioz - praepositus ........ 1637-1639

4. Nathias Blallobrzeski - Vlcarius ....... 1639-1643

5. Stantslaus Kublelow10 - " ........ 1642-1646

6. Paulus Drankierioz - " ....... 1644-1652

7. Paulus Nabrzesh - ....... 1646

8. Math18s Kqkolsk1 - ....... 1647-1648

9. Adamus Vladislaus Sleńletevioz - vioarius .... 1648 10. Stanislaus Czerniewsk1 -

1648 
11. Mathias Popowgld - vioarius ....... 1649-1654

12. Guillelmus Desdames - parochus....... 1654-1657

13. Joannes Probolowak1 - Vloarius ....... 1654-1657

P I z y g 1 \& y

1 Niniejszy artyluz jest rezultatem pierwszego etapu badań

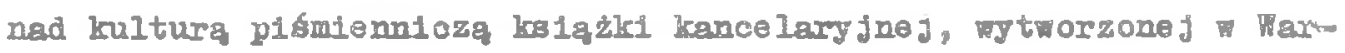
szamia p plermezej pozowle zVII w. przez organizacje kof́cielne,

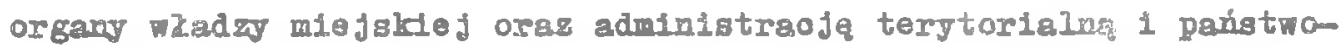
พa.

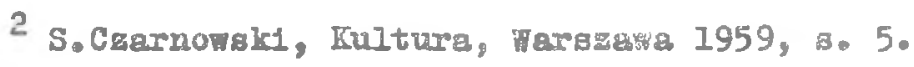

3 Analiza metryk pararialnyoh z XVI-IVIII w. Polsce w aspekcle 1ch pryydatnosol do badál demografioznyoh zob. I. Gleysztom rowa, Wstęp do demegrafli staropolskiej, Warsiama 1976, s. 198260.

4 J.Iowackl, Arohldiecezja poznańsica w graniosoh historjczmoh 1 jej ustrój, t. Ir, Poznań 1964, s. 587. Poi. B. Buse, Próba

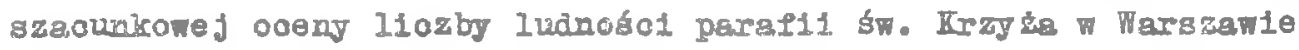
* lataoh 1626-1800 na podstawle los lag metrykalngoh, Pracs magism teraka napisana pod klerunkiem prof. S.Herbsta, 1969. Arohivum UW हyg. WH/SZH 25212.

5 S.Chodyhiki, Metrylt kof́cielne, พ: Bncyklopeda Kosolelna, t. XIV, Warazawa 1881, s. 224-231. Obowiazek rejestraoj1 rmarkych wpowadzony zostal w Polsce 1631 r., zob. B. Kumor, Hetryk1 paratialne wohiwech diecesfalnjoh, "Fwartalnik Historil Kultury Laterlalnef", B.14: 1966, A. 65-67. Najwcré́nlejaze zaohowane

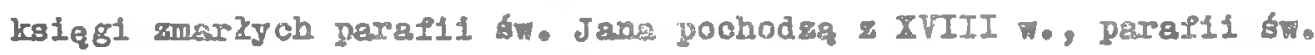
Irzyza - z drugioj pozowy XVII .

6 -11bri duo emantur in quibus baptisatorum nomina et eorwm qui in facte ecolesiae trimonlum oontrahunt sorlbantur iurta forman traditan in synodo gnesnensi Lovitil A.D.1593 celebrato". J.Sawlokd, Conclila Polonlae, t.V, Warsqawa 1950, s. 178.

$?$ Zob. Aneks I.

8 S.Siniarskanceaplioka, Fillgreny papierni pozotonych na obszarze Rzeczypospolited Polskiej od poozsticu XVI do pozowy XVIII wleku, Wroolaw 1969, s. 10. 
9 Ibidem, 8. 16.

10 Ibiderg, s. 19.

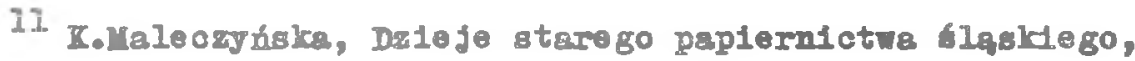
Mroola 1961, s. 172. K.Sarneck1, Zaopetrzente - papier verazanokiej drukarni Jana Bosowiklego z lat 1626-1634, "Przeglgd Papierafozy" R.7: 1964, s.230-231.

12 J.Sintaraka-Czaplicka, Filigranj papierni..., s. 9. K. Badeckt, znald wodne ksiagech Arohtwum miasta Iwowa 1382-1600, Lัพ́์ 1928, B.18.

13 I. Sarneoki, Zaopatrzanie wapier ..., s. 230. K. Badeok1, znald wodne..., B. 14. C.H. hriquet, Ies Illigranes. Diotionnaire historlque des marques du papier dés lour apparition vers 1282 Jusqu" in 1600, Le1pz1g 1923, t.4, 674-675.

14 J.SIniarglom-Ceaplioka, F1ligraxy papiern1..., s. 19.

15 zrak wodry ala many J.S1niarsklej-Czaplicklej, X. Badeokemu anj K. Sarneckiemu; nie me go równiez albumie Briquet"a ant Ilcheozevs.

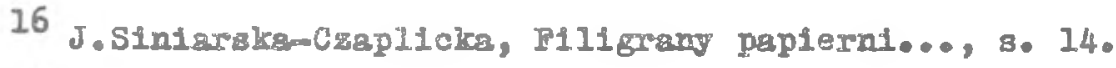

17 Por. C.ll. Briquet, Les I1l1 granes..., t.III, s.539.

18 K.Maleorysice, Drteje..., 8. 172.

19 zob. praypis 15.

20 B. Knmor, Metrylet paraflalne..., s. 67.

21 LBJ 2, 8. 50, 89, 167 oraz LBJ 5, 8. 279, 331.

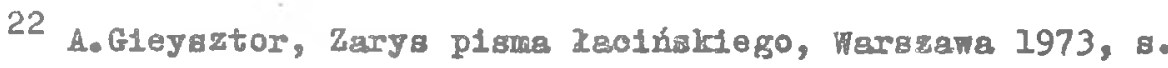
$191-193$.

23 IBJ I, 8. 399, 340, 343, 347, 350.

24 B. Kumor, Metryki paraflalne ...., 8. 67.

25 "In nomine Dominl annas Domini 1594 inoiplt felloiterm LBJ 1, s. 167; "Inclp1t novas annus in Jezu nomino 1611" LBJ 2, 8. 167.

26 Ip. wpisy z lat 1623-1628, IMJ 2 orgz $z$ 1635 r., LBJ 4. 27 两 1591 r. wplay koúcza s1ę 14 maja, IBJ 1, .. 126. 
28 LBJ I, . . 55, 56, 165, 274, 276, 279; INJ 1, 8. 86, 126,

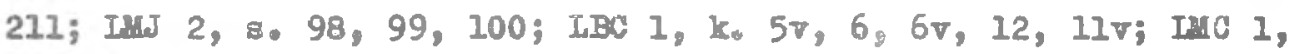
k. $17,18,29$.

$$
\begin{aligned}
& 29 \text { LBJ 1, 8, } 81 \approx 1589 \mathrm{r} \text {. } \\
& 30 \text { LBJ 1, 8. } 109 \text { z } 1590 \text { r。 } \\
& 31 \text { Dwa wpigy tego samego w1karlusza \& } 1606 \text { r., IBJ 2, в. } 88 . \\
& 32 \text { IBJ 1, 3. } 79 . \\
& 33 \text { LBT 2, 8. } 28 \text { \& } 16 \times 1603 \mathrm{r} \text {. } \\
& 34 \text { IBV 5, . } 159: 3 \text { IV } 1644 \mathrm{r} \text {. } \\
& 35 \text { LBJ 5, 342-343. }
\end{aligned}
$$

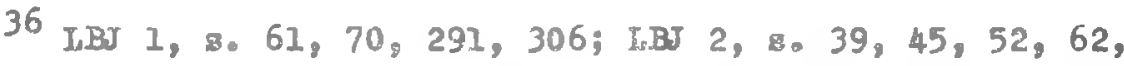
105, 164; LBJ 4, 8. 122, 1.43, 153, 183; LBC I, 上. 107, 18, 25.

37 INW 3, 9. 46 .

38 I 2 , . $126-127 \approx 19 \times 1653$ ×.

39 IMC 1, k. 9.

40 Iac 1.

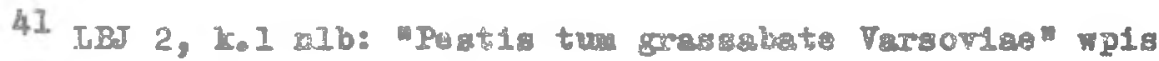
g 1602 I0, IMJ 2, s. 56: "H10 ism propter pestem dispersi sunt

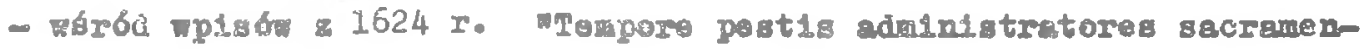

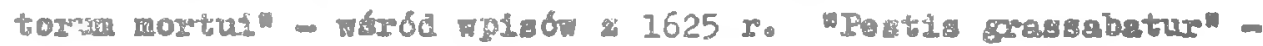

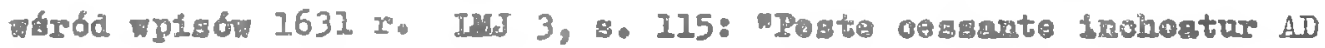
1653". INJ 3, s. 178: Conf1rmatt pater Abertus Clelqoul viearius - terpore oooupation1s a Srooig matrimonium - - vpls z 13 IX $1655 \mathrm{r}$.

42 roleglate - kosolox, proy ktorym istniaca kapitaza kole-

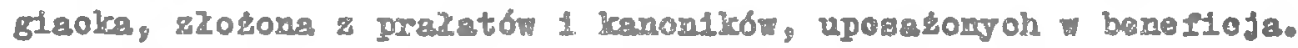
Poza obowiazican wobo kosoloke roleglaokdego 1 funkejand liturgioznymi nie odgrywals w1Qlksgej roli w sirukturze organteroyjnej diecezj1. Ale z niej mzante wyodzill sie lub byli zwiazani prqez posiadane benefiofa arohidiakonl oraz ofiojazowie, Itoryoh

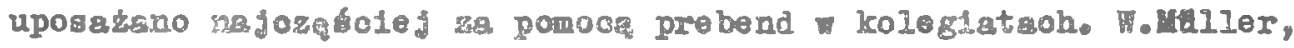

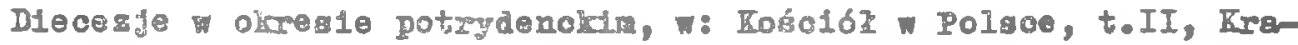
ków 1970, 日. 156-157. 
43 Do 1797 r. arohidiakonat warszamski wohodziz w skzad diecerji poznariklej. J.Nowackl, Arohidieoezja poznaniska..., s, 730. 44 Jw., s. 730.

45 Wikarlusze paralialni, w: Podręorna Bnoyklopedia Koscielna, t. III-XIII, Farszawa 1915, s. 284.

46 Zob. Aneks II. Daty zamieszczone przy kazdjm nazwiska wskazuja na daty skrajne wis6́n, sporzadzonyoh przez danego kaplana lub dotjozaojoh go jako oelebrensa 1 uozestnika ceremonif. Mansjonarze - ozlonkowie kolegín zobowiazzani do kjola wspólnego 1 atazej rezydencji przy danym kosolele oraz zgodnie z wola fundatora do odpramiania oodzlengyoh modiltw - jego 1ntenoj1. Altaryém o1 - księza uposazeni z fundacj1 zwiazanej z oztarzami. S. Litak, Struktura 1 Punkoja parafil : Polsoe, w: Kosoló w Polsoe, t.II, Krakón 1970, s. 328-330. Paałterzý́ol - koleg1a glozone a księźy luk ludgl ślioclech, fundowane w colu nśvietnlenia nabozeństw śpiewem. A.Pęsk1, w: Bnoyklopedia Kobolelna, t. 26-27, Fargzama 1903, s.213-218.

47 IES 4, s. 104-128.

48 IHe 3, s. 114.

49 zob. Aneks II.

50 S.Litak, Struktura..., 8. 348. I.Giejsztorowa, Wstęp..., 8. $220-231$.

51 Hazw miejsoowobol ustalono na podstewie publikacj1: Atlas Historjozny Polski. Lazowsze druglej pozowie IVI wieka, Farseawa 1973. 